Article

\title{
Transition to Sustainability in Macro-Universities: The Experience of the National Autonomous University of Mexico (UNAM)
}

\author{
Ken Oyama ${ }^{1}$, Ayari G. Pasquier ${ }^{2, *}$ and Edgar Mojica ${ }^{2}$ \\ 1 Escuela Nacional de Estudios Superiores (ENES)-Morelia, UNAM, Morelia 58190, Mexico; \\ kenoyama@unam.mx \\ 2 Secretaría de Desarrollo Institucional, UNAM, Mexico City 04510, Mexico; emojica@unam.mx \\ * Correspondence: ayari.pasquier@unam.mx; Tel.: +52-55-5622-1187
}

Received: 25 October 2018; Accepted: 15 December 2018; Published: 18 December 2018 updates

\begin{abstract}
In this paper, we assess the challenges of macro-universities to incorporate sustainability as an integral dimension of their activities and institutional development, and as a public higher education institutions that have an important role in sustainable development in the Global South. To this end, we analyzed the efforts oriented towards incorporating sustainability into research and teaching agendas, as well as the campus management activities of the Universidad Nacional Autónoma de México (UNAM), a university with national presence and a community of more than 420,000 people comprising students, academics and administrative staff. UNAM has historically been one of the most important research and teaching institutions in Latin America. The analysis incorporates quantitative and qualitative data, relying on information sources such as the databases of the University regarding research and teaching, institutional documents and interviews with key actors. This study argues that inter-institutional articulation is a key factor to integrate the increasing sustainable initiatives promoted in the last decade but also one of the main challenges in the consolidation of macro-universities as sustainable universities.
\end{abstract}

Keywords: sustainable university; public university; macro-universities; institutional design; global south; Mexico; UNAM

\section{Introduction}

The importance and potential contributions of higher education institutions (HEIs) to sustainable development were formally recognized since the early 1970s in the Club of Rome report (1972) [1] and the Stockholm Declaration (1972) [2]. However, it was not until the 1990s that universities began to formally commit themselves to the development of a sustainable world. One of the first and most important initiatives in this regard was the Talloires Declaration (1990) [3], a ten-point action plan for incorporating sustainability and environmental literacy in teaching, research, and campus management that has been ratified by more than 500 colleges and universities around the world. This first initiative was followed by many meetings, statements and reports, as well as the founding of international associations focused on promoting sustainability in universities. More recently, these efforts have been endorsed within the framework of the 2030 Agenda [4], composed by 17 goals and 169 targets through which the United Nations seek to promote sustainable development worldwide. This Agenda identifies universities as key actors for the generation of knowledge and the education of future leaders, decision makers, entrepreneurs and citizens and proposes that the incorporation of sustainability in the governance, management and culture of universities is valuable in itself and has potential value for the implementation of sustainable trans-sectorial initiatives. 
Over the last two decades, HEIs have progressively introduced sustainability into research, academic plans and campus management $[5,6]$. Some of them have achieved substantial progress in this process; in general terms, however, the progress has been uneven if we consider the different topics included in the idea of a sustainable university or the realities of HEIs in the world, and there are still many challenges to overcome [7], especially for HEIs in the Global South, a subject that to date has received little attention.

This paper analyzes the challenges faced by macro-universities for integrating sustainability into their substantive tasks through the case of the Universidad Nacional Autónoma de México (UNAM). The preliminary results of this research were presented at the 2018 International Sustainable Campus Network Conference. We consider macro-universities as those universities that: Have the highest enrolment rates nationwide; cover different areas of knowledge in the natural and social sciences, technology, humanities, arts and culture; conduct research and postgraduate teaching tasks in national and international arenas; receive a significant percentage of the national budget of the higher education system; and are in charge of the custody and development of important national historical and cultural heritage [8].

For the development of our case study we propose the following research questions:

- What progress has the UNAM made in the incorporation of sustainability in its substantive tasks (teaching, research and extension of culture) and the management of its campuses in the last 10 years?

- How have these initiatives contributed to the transformation of UNAM into a sustainable university?

- What are the main challenges that this institution faces in order to consolidate itself as a sustainable university in the future?

\section{Literature Review}

The literature on sustainability in universities has developed widely in recent years. The main topics discussed in these studies are: Management tools for green campuses, contributions of universities to sustainability and education for sustainable development [9]. The analysis of the challenges faced by HEIs in consolidating themselves as sustainable universities has also been central topic in this literature. Following Brandli et al. (2015), we distinguish between external and internal challenges [10]. The main external factors identified are the lack of interest and commitment of government bodies and the public in sustainability [11,12]. Amongst internal factors, the lack of interest of university authorities and the consequent lack of resources dedicated to this area $[9,13-15]$ stand out for their importance. The low priority given to sustainability in the management and development of universities translates, in turn, into the absence or inefficiency of a sustainability office responsible for promoting and coordinating activities linked to sustainability in universities $[12,16]$. The literature explains this situation by referring to the lack of knowledge on the importance and implications of the sustainability of universities $[17,18]$ and on the potential of sustainable management strategies to minimize costs and recover investments. Other obstacles frequently mentioned in the literature are the lack of planning $[10,15]$ and management instruments $[15,19]$ to integrate sustainability into university activities, as well as the absence of specific goals [20] and monitoring mechanisms to measure the achievements made [21]. Some authors also point out that although a growing number of HEIs are making efforts to include sustainability in their planning and activities, the analysis of the sustainable development plans and strategies of universities shows that they often lack a holistic vision of sustainability $[12,17]$ and that they usually prioritize the teaching and the operational management of university campuses [18], whereas they neglect research and culture [21]. In this investigation we are particularly interested in the discussion of the conditions that affect the organizational change for sustainability to become a "whole institutional approach" in higher education institutions, as outlined by the United Nations Educational, Scientific and Cultural Organization (UNESCO) Global Action Programme on Education for Sustainable Development [22]; an important emergent field of research $[23,24]$. 
Speaking specifically about research, the literature highlights that promoting interdisciplinarity has been difficult because universities still have a disciplinary structure $[5,25-28]$ and academics have been trained in disciplinary traditions and lack epistemological, methodological and theoretical tools to establish an interdisciplinary dialogue and develop problem-oriented approaches [14]. Furthermore, publications and academic evaluations are mostly organized following disciplinary criteria and there are not enough incentives for researchers to become involved in interdisciplinary collective projects [29].

In regard to teaching, the importance of developing specialised study programs on sustainability issues is underlined and, at the same time, introducing sustainability in all the study programs. This process is considered a key indicator of universities' commitment to sustainability, yet it is recognized that universities face great challenges $[30,31]$ in the construction of an interdisciplinary practice, and the integration of sustainability as a part of the knowledge and teaching tools of teachers [32]. To date, the development of new programs focused on sustainability issues has been successful, but the introduction of sustainability as a transversal dimension in academic offers shows slower progress. The main factors that have hindered this are the lack of a clear institutional mandate to consider sustainability as a transversal element of the academic offers of universities and the institutional capacity to act and acquire the necessary academic tools to do so [33].

Regarding the operational management of campuses, the literature identifies as central obstacles the diversity of uses of university facilities, including research offices, laboratories, classrooms, libraries, coffee shops, auditoriums, sports facilities, and administrative rooms; the divergence of interests between researchers, students and administrators [12-14]; and the lack of implementation of sustainable technologies. Such technologies, aside from improving the efficiency of resource use, contributes to the diffusion of sustainability principles in the university community and allows developing strategies that can be implemented in other contexts, following the model known as 'living lab,' where university campuses are considered privileged spaces for applied teaching and research around sustainability [34,35].

\section{Case Study Description}

As stated above, this paper reports a case study focused on the process of incorporating sustainability into the substantive tasks of UNAM, the main university in Mexico and one of the most important research and teaching institutions in Latin America. UNAM was formally constituted as a public university in 1910, although its history dates back to 1551 [36]. Its central campus is located in Mexico City, a large and complex urban area with important social and environmental challenges [37,38]. This campus, known as Ciudad Universitaria (CU), was inaugurated in 1952 and has an extension of 730 hectares, $32 \%$ of which is occupied by an ecological reserve. In 2007, the central area of $\mathrm{CU}$ was acknowledged by the United Nations Educational, Scientific and Cultural Organization (UNESCO) as a world heritage site, describing it as:

“[...] an exemplary monumental set of twentieth century modernity that integrates urbanism, architecture, engineering, landscaping and arts, associating these elements with references to local traditions and to the pre-Hispanic past of Mexico. The set embodies social and cultural values of universal significance and has become one of the most important symbols of modernity in Latin America." [39]

$\mathrm{CU}$ is home of an important part of the activities of UNAM, but the University also has other eight higher education campuses and 14 high schools in the metropolitan area of Mexico City, aside from six campuses for regional development and multiple research units in other states in the country, with a comprehensive community of more than 420,000 people comprising students, academics and administrative staff [40]. Given its public nature and its human, physical and financial resources, UNAM has a great potential to influence the sustainable development of the country through its activities of research, teaching and extension of culture. 
Our analysis shows that UNAM has been a fruitful space for initiatives linked to sustainability in research, teaching and campus management over the last 10 years. However, it also suggests that until now the University has not succeeded in transforming the multiplicity of existing initiatives in the field of sustainability into a sustainable university project. Based on this case study, we suggest as a research hypothesis that the large size and organizational complexity of macro-universities scale up the organizational obstacles faced by universities to consolidate themselves as sustainable universities, and therefore, that inter-institutional coordination for sustainability it is a particularly important factor to consolidate sustainable university projects in this kind of higher education institutions.

Understanding the challenges and opportunities faced by macro-universities when integrating sustainability in their tasks is relevant for different reasons. Given the extent of their enrolment and resources, these institutions have an important potential to spread the principles of sustainable development, contribute to a better understanding of complex socio-environmental problems, develop innovative technological and organizational responses to address sustainability challenges, and train high-level professionals in this field. Moreover, given their social prestige, these universities can also have an important leadership for the promotion of sustainable practices in the cities where they are located [41-43]. In Latin America, we have identified 37 higher education institutions with these characteristics. There are, no doubt, similar institutions in other regions of the world, although, we do not have enough information to date to identify them. Taking into account only the number of students, there are at least 20 universities with an enrolment similar or superior to that of the UNAM worldwide, these are mostly located in Asia, it should be noted that an important part of the enrolment of some of these universities corresponds to distance education schemes.

\section{Materials and Methods}

The term 'sustainability' has been widely used in several fields, and different definitions have been developed over the past decades. Our analysis uses a broad definition of this concept that takes into account two of the elements around which there is greater consensus in the literature: (1) The reference to a scheme of use and management of ecosystems and natural resources that does not compromise their future survival persistence and (2) the integration of environmental, social and economic dimensions in academic analysis and problem-solving proposals. The operative definition of the areas and actions that can be categorized as 'sustainable' in a university implies methodological decisions that are reflected in the monitoring of their performance and the definition of priorities for their management. The present study considers in this field research, teaching and campus management activities linked to natural resource knowledge and management, environmental impacts of human activities and explicit references to the term 'sustainability.' The data for this research and its treatment are described below:

(1) We identified databases that contained information about the activities of research, teaching, culture and operation of university campuses in the last decade. To analyze these databases:

- We defined over 100 keywords (in Spanish and English) from the analysis of the main international treaties linked to sustainable development.

- We first undertook a categorization exercise based on an automated word search.

- We conducted a qualitative review of the first classification to ensure that the selected records were associated with sustainability.

- We graphed the databases resulting from this last step to infer the behavior of the number of initiatives linked to sustainability in the areas analyzed (teaching, research, extension of culture and campus management).

The databases analyzed with this procedure are listed below:

- The plans, study programs and courses were consulted in the database of the UNAM General Directorate of School Administration (DGAE). 
- The theses were consulted in TesiUNAM, a database that digitally registers all the theses of the University.

- Research projects carried out by the UNAM researchers was consulted in the database provided to us by the UNAM General Directorate of Institutional Evaluation (DGEI).

- Publications of UNAM academics were consulted in the Web of Science database.

- The continuing education activities were consulted in the UNAM Coordination of Open University and Distance Education (CUAED) database.

To complete the information obtained through the analysis procedure previously described we consulted various qualitative sources that we analyzed through a content analysis approach:

(2) The institutional pages of all the academic dependencies of the UNAM, to know their research lines, programs and departments.

(3) The last 10 annual reports of all the academics and administrative entities of the University, to identify infrastructure initiatives related to sustainability, to know if they were documented as part of a larger project and whether they were followed up in the years after their first appearance.

(4) Meetings with data managers about campus operations and with different actors who have promoted or have been responsible for sustainability initiatives over the past few years.

The data collected in our research have different limitations, especially those that concern the operation of the campus. It should be noted that at the UNAM there are still no institutional practices concerning the reporting of initiatives linked to sustainability and, as result, information, when available, is scattered and fragmented. This situation imposed certain limits to the methodological design of our study, which is mainly an exploratory study that sought to make a diagnosis of the initiatives linked to sustainability that were carried out at the University over the last decade. For this same reason, we do not have the elements to thoroughly investigate our hypothesis and develop a strategy to accept or reject it. However, the information obtained allows us to better understand the analyzed process and provide valuable elements to improve the institutional design of the UNAM and other macro-universities to consolidate themselves as sustainable universities.

\section{Results}

According to the latest data, UNAM has 349,515 enrolled students, 40,578 academics and 30,024 administrative employees. The teaching and research activities of the University are articulated through 15 faculties, five multidisciplinary units and eight national schools, 14 high schools, 34 research institutes, 14 research centers and 10 research programs. UNAM also has 135 libraries, 26 museums and 18 historical precincts under its charge. This section describes the main initiatives linked to sustainability developed at the UNAM in the last 10 years. The presentation of this data is organized in five sections: Specialised Research and Teaching Centers, Teaching, Research, Continuing education and communication of science and Campus management; through this exercise our first research question was, namely: What progress has UNAM made in the incorporation of sustainability in its substantive tasks and the management of its campus over the past 10 years? The following section discusses some of the most important implications of the size and organizational complexity of the University in relation to efforts to foster processes of institutional innovation towards sustainability; addressing the other two questions that we initially raised: How do these initiatives contribute to the transformation of UNAM into a sustainable university? Finally: What are the main challenges facing the consolidation of these initiatives in the future?

\subsection{Specialised Research and Teaching Centers}

UNAM has five research entities focused on sustainability, their creation is one of the best examples of the institutional support for the development of research and teaching in the sustainability field at UNAM. Table 1 list their names, the years when they were founded, the year of their first institutional 
background and their location. Besides, there are also more than 30 entities with departments or lines of research related to sustainability that are explicitly mentioned in their official documents, as well as many other faculties and institutes with academics who individually work on research related to this field. The main research topics are climate change, biodiversity and biological conservation, sustainable technologies, analysis of pollutants, environmental restoration, political ecology, environmental governance and policy.

Table 1. Research entities specializing in the study of the environment and sustainability.

\begin{tabular}{lccc}
\hline \multicolumn{1}{c}{ Name } & $\begin{array}{c}\text { Institutional } \\
\text { Background }\end{array}$ & Foundation Year & Location \\
\hline Ecosystems and Sustainability Research Institute & 1996 & 2003 & Morelia, Michoacán \\
Environmental Geography Research Center & 2003 & 2007 & Morelia, Michoacán \\
Climate Change Research Program & - & 2009 & CU, Mexico City \\
Renewable Energies Institute & 1985 & 2013 & Temixco, Morelos \\
National Laboratory of Sustainability Sciences ${ }^{1}$ & - & 2014 & CU, Mexico City \\
\hline
\end{tabular}

${ }^{1}$ A part of the Institute of Ecology.

\subsection{Teaching}

UNAM has an enrollment of 349,539 students: 59\% undergraduate, $9 \%$ graduate and $32 \%$ high school (DGAE, UNAM, 2018). The teaching activities and training opportunities at the University have evolved for more than a century, integrating a wide variety of perspectives and institutional actors. Its academic offer actually includes 41 postgraduate, 123 bachelor's degrees, 36 technical careers and two high school programs.

The international agreements linked to sustainability in universities consider both the inclusion of study programs specifically focused on this area and the inclusion of sustainability as a transversal dimension of the educational offer of HEIs as important, since all disciplines can contribute to sustainability. However, as it was noted above, the literature identifies this as one of the most complex areas in the process of building a sustainable university. During the past decade, UNAM has incorporated sustainability in its training offer both through the creation of programs focused on sustainability and by means of the incorporation of courses on sustainability in pre-existing programs. This process has taken place from the 2000s, and especially from 2010. Currently, $6 \%$ of undergraduate and graduate programs are focused on sustainability, $18 \%$ have an area of specialisation on this subject, $40 \%$ include courses related to the field while $36 \%$ have not yet incorporated the perspective of sustainability in any way. Figure 1 shows the distribution of undergraduate and graduate programs classified by their link to sustainability of their objectives and curricular plans.

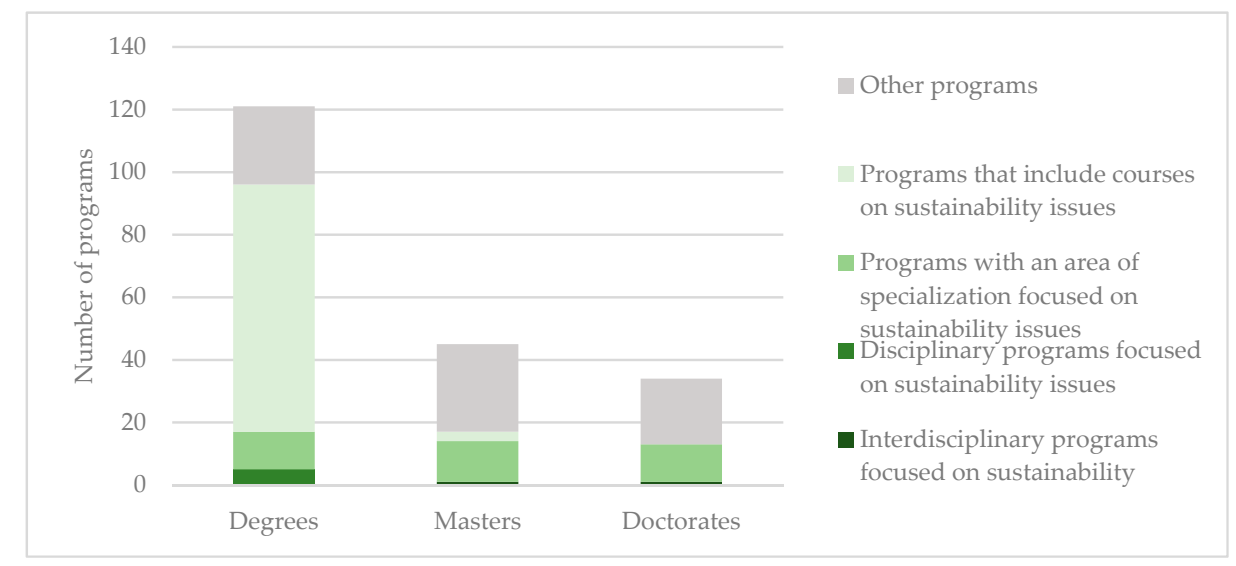

Figure 1. Study programs by their link with the environment and sustainability, Universidad Nacional Autónoma de México (UNAM) 2018. Note: PhD programs do not include obligatory courses. Elaboration based on http:/ / www.posgrado.unam.mx. 
These data show the contributions of UNAM to the training of experts on issues related to sustainability. However, the transversal incorporation of the topic in the academic offer of the University is still partial, and until now, disciplinary approaches have been privileged, both in the field of the natural sciences and in the social sciences. Considering the limits of disciplinary approaches in the field of sustainability, in 2015, the University created a postgraduate program in sustainability sciences, an interdisciplinary program focused on the study of sustainability problems and the development of applied research. Until 2017-2018, this postgraduate program had 157 Master's students (of which 26 had already graduated) and $57 \mathrm{PhD}$ students. Table 2 lists the academic offers of UNAM linked to sustainability at the undergraduate and graduate levels.

Table 2. Specialised study programs and programs with an area of expertise in the environment and/or sustainability.

\begin{tabular}{lc}
\hline \multicolumn{2}{l}{ Interdisciplinary programs focused on sustainability } \\
\hline Postgraduate programs & Sustainability Sciences \\
\hline Specialised study programs on the environment and/or sustainability \\
\hline Undergraduate programs & $\begin{array}{l}\text { Sustainable Management of Coastal Zones, Engineering in Renewable Energies, } \\
\text { Environmental Sciences, Sustainable Materials Sciences, and Environmental } \\
\text { Engineering. }\end{array}$ \\
\hline Specializations & $\begin{array}{l}\text { Savings and Efficient Use of Energy, Environmental Law and Environmental } \\
\text { and Ecological Economics. }\end{array}$ \\
\hline Study programs with an area of expertise in the environment and/or sustainability \\
\hline Undergraduate programs & $\begin{array}{l}\text { Biology, Ecology, Earth Sciences, Geophysical Engineering, Technologies for } \\
\text { Information in Sciences, Agricultural Engineering, Chemistry, Industrial } \\
\text { Chemistry, Agricultural Administration, Law, Territorial Development, } \\
\text { Geohistory and Architecture. }\end{array}$ \\
\hline $\begin{array}{l}\text { Earth Sciences, Engineering, Physical Sciences, Biomedical Sciences, Teaching } \\
\text { for Higher Secondary Education, Biochemical Sciences, Biological Sciences, } \\
\text { Marine Sciences and Limnology, Chemical Sciences, Law, Economics, } \\
\text { Geography, Architecture and Urbanism. }\end{array}$ \\
\hline
\end{tabular}

The incorporation of study plans and programs focused on sustainability has been reflected in the increase in thesis projects related to the topic, especially in programs focused on the environment. We identified 5594 theses linked to sustainability between 2008 and 2016, 5.6\% of the theses concluded during this period. It should be noted that more than 200 of these theses were written within the framework of study programs that do not include any subject related to the environment or to sustainability, showing areas of opportunity to consolidate the inclusion of this topic in the curricular offer of the University. These theses come from different programs, such as Actuary, Visual Arts, Computer Science, Latin American Studies, Philosophy, History, Mathematics, Medicine and Odontology and Pedagogy.

\subsection{Research}

The UNAM reported 7783 research projects between 2008 and 2016. The research areas with the largest number of projects at the University are Physics, Engineering, Biochemistry and Earth Sciences. In this period, we identified 540 projects focused on issues related to sustainability. A total of $82 \%$ of the projects were focused on research and $12 \%$ were oriented to the development of teaching materials and knowledge dissemination activities. The main subjects addressed in the research were structure and functions of ecosystems (18\%), pollution and sanitation (10\%), sustainable technologies $(7 \%)$, renewable energy $(7 \%)$, climate and global change $(6 \%)$, biodiversity $(6 \%)$ and sustainable production systems ( $4 \%$ ). Of these projects, $80 \%$ were financed by UNAM and the remaining $20 \%$ by the National Council of Science and Technology (CONACYT). 
Figure 2 shows that since 2011, the number of projects developed in this field has significantly increased. Fifty percent of the research projects identified as related to sustainability belong to the areas of Biology and Chemistry, 31\% to Physics and Mathematics and 10\% to Social Sciences and humanities. Only $1 \%$ of these projects were registered as multidisciplinary research. The most frequent disciplines involved in these projects are ecology, biology and earth sciences, whereas Economics is the only discipline in the area of the Social Sciences and Humanities with 10 or more projects related to sustainability in the period analyzed.

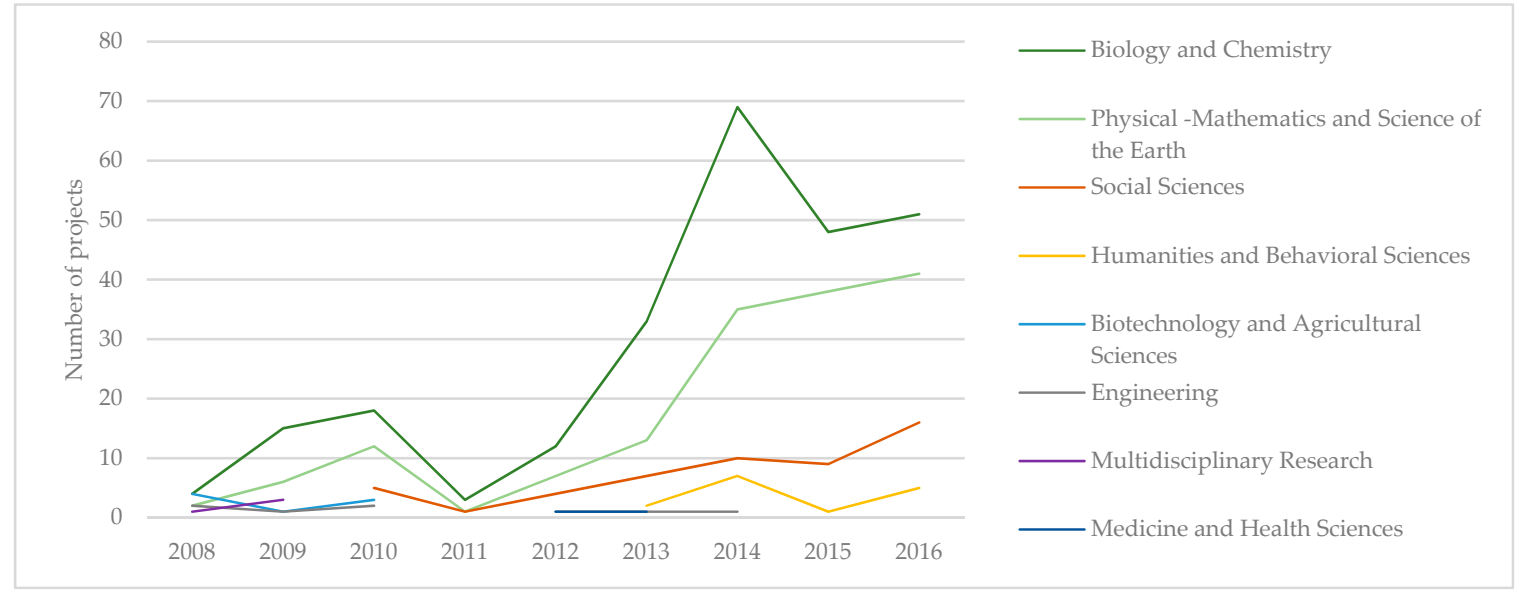

Figure 2. Research projects linked to sustainability by year and area of study, UNAM 2008-2016. Note: Elaboration based on the databases on research projects of SIIA, UNAM.

Based on the Web of Science database, we estimated that between 2008 and 2016 UNAM researchers published 39,881 , these papers represent almost $28 \%$ of the scientific publications of the Mexican academy in that period. Between these, we identified 3346 publications related to sustainability, $8.4 \%$ of the publications produced by UNAM researchers in that period. Like the projects, the publications that deal with issues related to sustainability have also increased in recent years. Figure 3 shows the increase in the number of publications related to this field between 1980 and 2017, particularly accentuated in the areas of Biology and Chemistry.

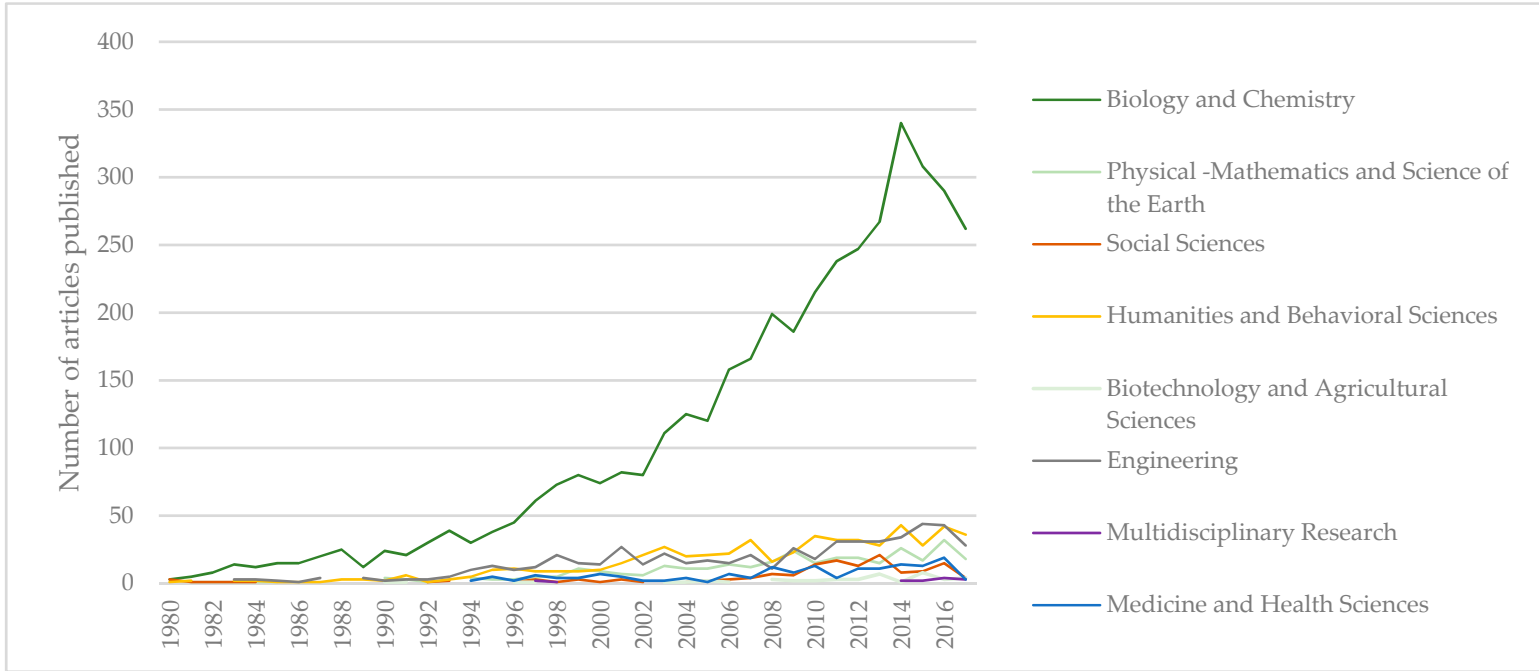

Figure 3. Publications related to the environment and sustainability written by UNAM academics by field of knowledge for the period 1980-2017 based on the Web of Science database. Note: Elaboration based on WOS, 2018. 
Again, it is important to note the low number of publications in social sciences related to sustainability. These data show that research at UNAM still has a long way to go in order to build an interdisciplinary practice in sustainability studies and suggests the need for institutional guidance and support to promote and strengthen collaboration between research centers integrating social, economic, ecological and technical disciplines in the field of sustainability to consolidate UNAM's potential contributions to address sustainability issues.

\subsection{Continuing Education and Communication of Science}

UNAM holds more than 100 events a year related with sustainability open to the researches, the students and the general public, it should be noted that the CUAED database includes detailed information only of around $10 \%$ of these events. Figures 4 and 5 show some trends regarding these events in the last decade based on the available data.

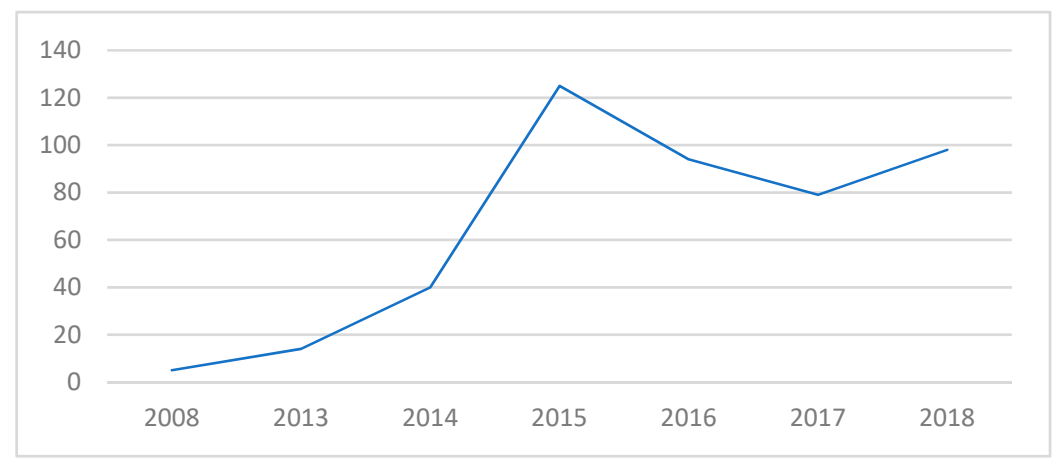

Figure 4. Continuing education and communication of science activities at UNAM by year. Note: Elaboration based on the databases on research continuing education of CUAED, UNAM.

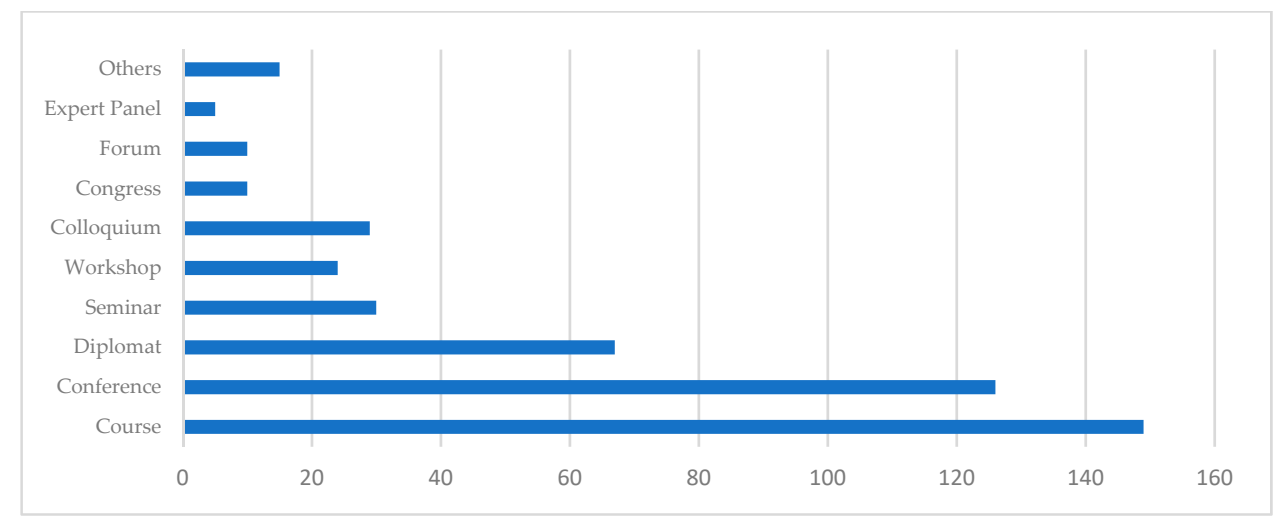

Figure 5. Continuing education and communication of science activities at UNAM by type. Note: Elaboration based on the databases on research continuing education of CUAED, UNAM.

The University also has three permanent seminars related to this field that organize periodic meetings on specific topics: The University Seminar on Hydrocarbon Research, the University Seminar on Socio-Environmental Risk Studies and the University Seminar on Society, Environment and Institutions. The last two of them have a multidisciplinary approach and have made various initiatives that seek to position the environmental agenda in the public debate.

The most important unit of the University in terms of communication activities related to sustainability is the Science Museum 'Universum,' located within the main campus, which houses several permanent and temporary exhibitions of these topics and offers courses and workshops related to environmental issues. The University has another four museums that focus on these subjects: The Zoology museum in CU, and the Geology museum, the 'Chopo' museum and the 'Casa del Lago'; all of them located in the downtown area of Mexico City. 


\subsection{Campus Management}

In the last 10 years, different initiatives have been carried out to improve sustainability in the management of the UNAM campus. However, no database concentrates this information and no general report has been made to concentrate this data. Through a content analysis of the section dedicated to the infrastructure of the reports of the entities and dependencies, for the last decade we identify at least 24 different projects that address different areas of management and 854 mentions to different sustainable management initiatives. It should be noted that there is no follow-up mechanism to these initiatives, some of these are short-term initiatives and others have been ongoing for years, but this information is not available. The largest number of initiatives reported are linked with energy and, secondly, water. Figure 6 shows the distribution of these initiatives distinguishing them by area and the year they were reported. Most of these initiatives have taken place in $\mathrm{CU}$, the main campus of the University, but some of the new campuses of the University have been important spaces of innovation for sustainable management.

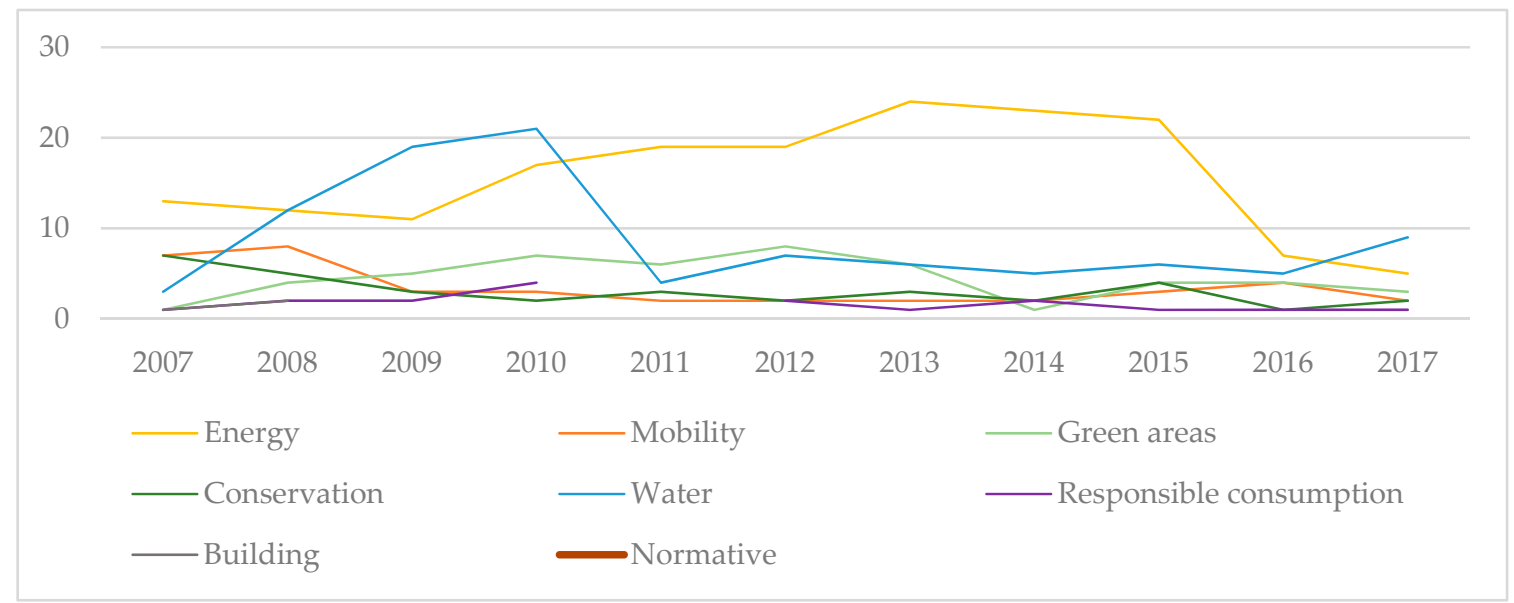

Figure 6. Reports of sustainable management of university spaces. Note: Elaboration based on the in the analysis of the annual reports of the entities and dependencies present in the "University Reports" published online (http:/ / www.planeacion.unam.mx/Memoria/).

This section describes some of the most important initiatives for the sustainable management of campus operations at UNAM.

\subsubsection{Ecological Reserves}

The campus of CU includes a natural reserve of 237 hectares (just over $30 \%$ of the campus extension), established in 1983 in order to protect a unique high-elevation xerophilous scrub ecosystem that hosts at least 1500 native species and 317 exotic species [43]. In addition to its contributions as a habitat for biodiversity, this reserve is an important area of water catchment for the south of the city, an area with continuous urban growth. It also makes contributions in terms of noise and temperature damping and $\mathrm{CO}_{2}$ uptake. The objectives of this reserve also include knowledge dissemination, research and teaching. In sum, this reserve is the only really protected natural area in the city of Mexico.

In addition, the UNAM is directly involved in the management of other five national reserves in the country, where it contributes to the study and conservation of ecosystems:

- $\quad$ The National Park Isla Isabel, Nayarit.

- La Isla Socorro, that is part of the Revillagigedo Biosphere Reserve, Colima.

- The Biosphere Reserve Chamela-Cuixmala, Jalisco.

- The National Park La Malinche, Tlaxcala. 
- $\quad$ The Biosphere Reserve Los Tuxtlas, Veracruz.

\subsubsection{Water Management at UNAM, Pumagua}

The water supply in the main campus comes from three wells given to the University by the National Water Commission. Considering the serious problems in efficiency of the water supply system in Mexico City, where losses up to $40 \%$ are estimated [44], the University created the Program of Management, Use and Reuse of Water in 2008 with the goal of achieving efficient water management within the University. This program considers three aspects: Hydraulic balance, water quality and promotion of social participation. As a part of this initiative the University also created the UNAM's Water Observatory [45], an open-access digital platform that tracks consumption and water leaks in real time. So far, this program has been implemented in the CU campus, where it facilitated a decrease in the average volume of extraction from 100 to $70 \mathrm{~L}$ per second between 2008 and 2016, despite the increase in the number of users from 131,682 to 185,000. A similar initiative began to be implemented in two teaching and research units located in the eastern and northern parts of the Valley of Mexico (the Faculty of Higher Education of Zaragoza and the Faculty of Higher Education of Acatlán). Pumagua has also been involved in projects outside the University and has been a place for students training in water management topics.

\subsubsection{Strategy for a Sustainable University at UNAM, EcoPuma}

In 2009, the University created a Strategy for a Sustainable University at UNAM. The main activities carried out within the framework of this initiative were an environmental hallmark for the university dependencies that make efforts to reduce their environmental impact and the design and implementation of the "EcoPuma" program [46], an initiative that promotes practices to reduce the environmental impact of the university campuses in the following areas: Waste, energy, water, mobility, green areas, construction, purchases and electronic administration. This initiative has promoted the sustainable management of campuses in the University and implemented some valuable initiatives, such as a waste management program, replacement of a part of outdoor lighting, publication of guidelines for sustainable construction and purchases, and various outreach activities. Yet, to date its capacity to influence the management of university campus operations is limited both in CU and in the rest of the campuses of the University in Mexico City and in the country.

\subsubsection{External Campus}

As noted in previous sections, the UNAM has multiple academic units in the country, including three external campuses (Morelia, Michoacán; Cuernavaca, Morelos; and Juriquilla, Querétaro) that integrate various research institutes and four National Superior Study Schools (Escuela Nacional de Estudios Superiores -ENES). Below we describe the most important initiatives towards sustainability in some of these decentralized venues.

- Campus Morelia, Michoacán.

This campus includes seven research units, three of them address sustainability issues: The Institute for Research in Ecosystems and Sustainability, the Center for Research in Environmental Geography and a Unit of the Institute of Materials Research focused on sustainable materials. This campus also houses a National School of Higher Studies (ENES) that offers 13 bachelor's degrees and five postgraduate degrees. Several of these programs have a close link with sustainability, between these: The degrees in Environmental Sciences, Ecology, Geosciences, Sustainable Materials Science, Social Studies and Local Management; and the postgraduate degrees in Biological Sciences, Earth Sciences and Sustainability Sciences.

The operational management of the campus also include principles on sustainability, particularly in the ENES, that was built more recently and considered sustainability in its architectural design and planning, implementing various strategies, such as the establishment of a wastewater treatment plant, 
a rainwater harvesting system, the installation of drinking water fountains to avoid the use of plastic bottles, an energy saving program, a solar panels for water heaters, a landscape project that decreases the water used for irrigation and contributes to the conservation of plant species, a waste management program that includes garbage composting and recycling, and a bicycle loan service.

- Campus Cuernavaca, Morelos.

This campus also includes seven research units, among them the Institute for Renewable Energies, that offers a degree in Engineering in Renewable Energy and participates in the postgraduate courses in Energy Engineering, Engineering in Materials and Physics. This campus also has two other research units where key issues for sustainability are addressed: The Institute of Biotechnology and the Regional Center for Multidisciplinary Research.

The main initiative for the sustainable operation of the campus is the separation of waste and the composting of organic waste through the Integral Solid Waste Management Program [47], which has been operating since 2014. Through this program, in 2017, the campus recycled 8 tons of urban waste (paper/cardboard, PET, bags, glass, tin, aluminum, batteries and iron) and transformed $90 \%$ of its food waste and $100 \%$ of its gardening waste into compost.

\section{- $\quad$ ENES León, Guanajuato.}

This ENES does not have an academic profile oriented towards sustainability, but it has incorporated sustainability in its campus management since its foundation. Its campus has a sustainability office [48] that promotes different initiatives, such as the installation of solar panels for outdoor lighting, a system for the free use of bicycles and the design of a bike path, a garden area with native plants irrigated with treated water contributing to the capture of rainwater, the installation of drinking water fountains and an electronic waste collection campaign organized by the students.

\section{Discussion}

The previous section shows that, over the last decade, multiple initiatives related to the environment and sustainability have been initiated at UNAM. Some of these have had a short-term nature, but many others are the result of institutional efforts to include sustainability as a priority of the University. This is the case with the formation of several research centers and study programs specializing in sustainability issues reported in the first two sections of our results. Another example is the formulation and implementation of strategies to reduce the environmental impacts of University activities in the design of some of the new UNAM campuses in the country, such as ENES Morelia and ENES Leon. However, until now, many of these initiatives have remained isolated and this has made it difficult to consolidate them in the long term. Besides, the existing initiatives respond, to a large extent, to the projects and interests of particular actors within the University and are not based on a general diagnosis of the advances and pending of the University in this field. The lack of an overall vision of the advances, priorities and challenges of the University to become a sustainable university makes it difficult for the University to address, in a systematic way, the pending tasks and overcome the obstacles for its consolidation as a sustainable university. Among the areas that the University needs to strengthen for this purpose, the present study suggests: To extend the academic offer in subjects related to sustainability at the undergraduate level and include subjects on sustainability in those programs that do not yet consider the subject, for example: Administration, Arts, Computer Science, Philosophy, History, Mathematics, Medicine and Pedagogy; to promote interdisciplinary research agendas around contemporary socio-ecological challenges; reformulate the campus management schemes to give priority to sustainable strategies in all university campuses and define indicators to monitor the performance sustainable management strategies implemented; to include students and the university community at large as key actors in the sustainability strategies of the University; and to enhance collaboration with public and social actors in order to address the sustainability problems of the cities and regions where the university campuses are located. 
The obstacles and opportunities that UNAM have faced and still faces in its efforts to incorporate sustainability into its substantive tasks and campus management are multi-faceted problems. From this case, we highlight the importance of a university joint project that guides the transition towards sustainability in universities [49-52] as part of the construction of a "whole institutional approach", as outlined by the UNESCO's Global Action Programme on Education for Sustainable Development [53]. Amongst the institutional challenges for the development of sustainable universities, researchers have identified the divergence between academics, students and administration staff members as a potential source of power struggles and divisions [54]. This discussion is relevant for all universities but is particularly important for macro-universities, such as UNAM, where visions and subgroups multiply, making the articulation of a sustainable university initiatives not only more complex but also more important. UNAM consists of more than 130 entities and dependencies with their own histories and contrasting visions about the priorities of the University and the role of and importance given to sustainability. The size and complexity of its organizational structure, the diversity of institutional actors and the institutional inertias that have developed over more than a century have hindered both the construction of a unitary sustainable university project and the implementation of a transversal program of sustainable campus management. At the same time, it is important to consider that the initiatives carried out in this field often receive positive responses from many members of the academic community and have a broad social demand, showing that there is a field of opportunity for the growth of these initiatives that the University has not yet fully responded to.

\section{Conclusions}

To better understand the process of incorporating sustainability into the substantial tasks of UNAM, one should begin by considering the common perception of sustainability in Mexico as an issue secondary to other social problems, such as poverty, lack of security and lack of democracy. This perception is present both in political areas and in multiple social spheres. It permeates the definition of research agenda and the teaching priorities within universities, underestimating the impacts of environmental degradation on quality of life and social welfare, as well as the fact that investments on sustainability are crucial for the present and for the future.

To contribute to the development of increasingly sustainable societies is one of universities' essential tasks in order to comply with their social responsibility, especially for public universities of the Global South. The UNAM Institutional Development Plan 2015-2019 acknowledges environmental crises amongst the main contemporary challenges faced by the University and commits to incorporate sustainability perspectives in teaching, research, communication and culture, as well as in the structural and operational aspects of its campus management. However, the lack of articulation of existing sustainable initiatives and the multiplicity of missing areas, discussed in the previous sections, suggest that the University faces institutional challenges in translating this political will and the broad set of initiatives implemented to date in a systematic and sustained process of transition towards sustainability.

This research confirms what has been exposed in other works that point out that to incorporate sustainability as a core dimension of academic activities and decision making in universities these institutions need to make important changes in their governance schemes [55] and identify organizational development as a key factor to strengthen transformational processes towards sustainability $[23,24]$, institutionalize it and ensure the continuity and consolidation of the sustainability projects over time. From the meetings we had with actors who have promoted or have been responsible for sustainability initiatives at UNAM, it seems clear that this demands not only clear leadership and will from university authorities but also the support of key actors at all organizational levels of the universities, processes of dialogue and construction of agreements to articulate existing initiatives, and an inclusive and participative strategy that involves students, academics and administrative staff members and that encourages collaboration within university communities. 
Among the topics of future research regarding the incorporation of sustainability in the substantive areas of the UNAM we consider important to highlight: A meta-analysis of research projects and publications to identify the most studied topics and those that still need to be promoted; a network analysis of the academics involved in these works and the extent to which they are incorporating interand trans-disciplinary methodologies; and the spaces and strategies used by researchers to link and influence local contexts.

Author Contributions: Conceptualization, K.O. and A.G.P.; Data curation, E.M.; Formal analysis, A.G.P. and E.M.; Funding acquisition, K.O.; Investigation, A.G.P.; Methodology, A.G.P.; Project administration, K.O.; Resources, E.M.; Supervision, K.O.; Validation, A.G.P.; Visualization, A.G.P., Writing—original draft, A.G.P.; Writing—review \& editing, K.O. and A.G.P.

Funding: This research received no external funding.

Conflicts of Interest: The authors declare no conflict of interest.

\section{References}

1. Meadows, D.H.; Meadows, D.L.; Randers, J.; Behres, W.W., III. The Limits to Growth. A Report of The Club of Rome's Project on the Predicament of Mankind; Universe Books: New York, NY, USA, 1972; ISBN 0-87663-165-0.

2. United Nations. Declaration of the United Nations Conference on the Human Environment; United Nations: Stockholm, Switzerland, 1972.

3. Association of University Leaders for a Sustainable Future. The Talloires Declaration; Association of University Leaders for a Sustainable Future: Pittsburgh, PA, USA, 1990.

4. United Nations General Assembly. A/RES/70/1 Transforming Our World: The 2030 Agenda for Sustainable Development; United Nations General Assembly: New York, NY, USA, 2015.

5. Lozano, R.; Lozano, F.J.; Mulder, K.; Huisingh, D.; Waas, T. Advancing higher education for sustainable development: International insights and critical reflections. J. Clean. Prod. 2013, 48, 3-9. [CrossRef]

6. Ramos, T.B.; Caeiro, S.; van Hoof, B.; Lozano, R.; Huisingh, D.; Ceulemans, K. Experiences from the implementation of sustainable development in higher education institutions: Environmental management for sustainable universities. J. Clean. Prod. 2015, 106, 3-10. [CrossRef]

7. Shiel, C.; Leal Filho, W.; do Paço, A.; Brandli, L. Evaluating the engagement of universities in capacity building for sustainable development in local communities. Eval. Program Plan. 2016, 54, 123-134. [CrossRef] [PubMed]

8. Estatutos de la Red de Macro Universidades de América Latina y el Caribe. Available online: http:/ /www. redmacro.unam.mx/estatutos.html (accessed on 10 August 2018).

9. Labanauskis, R. Key Features of Sustainable Universities: A Literature Review. J. Bus. Manag. 2017, 13, 56-70.

10. Brandli, L.L.; Leal Filho, W.; Frandoloso, M.A.L.; Korf, E.P.; Daris, D. The environmental sustainability of brazilian universities: Barriers and pre-conditions. In Integrating Sustainability Thinking in Science and Engineering Curricula; Filho, W., Azeiteiro, U., Caeiro, S., Alves, F., Eds.; Springer International Publishing: Berlin, Germany, 2015; pp. 63-74. ISBN 978-3-319-09474-8.

11. Perkmann, M.; Tartari, V.; McKelvey, M.; Autio, E.; Brostr€om, A.; D’Este, P.; Fini, R.; Geuna, A.; Grimaldi, R.; Hughes, A.; et al. Academic engagement and commercialization: A review of the literature on university-industry relations. Res. Policy 2013, 42, 423-442. [CrossRef]

12. Leal-Filho, W.; Jim, Y.C.; Wu, L.; Londero Brandli, L.; Veiga Avila, U.; Miranda Azeiteiro, S.; Caeiro, L.; da Rosa Gama Madruga, R. Identifying and overcoming obstacles to the implementation of sustainable development at universities. J. Integr. Environ. Sci. 2017, 14, 93-108. [CrossRef]

13. Bero, B.N.; Doerry, E.; Middleton, R.; Meinhardt, C. Challenges in the development of environmental management systems on the modern university campus. Int. J. Sustain. High. Educ. 2012, 12, 133-149. [CrossRef]

14. Alnsour, J.A.; Meaton, J. The use of university research in planning decision making in Jordanian municipalities. Habitat Int. 2015, 49, 206-211. [CrossRef]

15. Dahle, M.; Neumayer, E. Overcoming barriers to campus greening: A survey among higher educational institutions in London, UK. Int. J. Sustain. High. Educ. 2001, 2, 139-160. [CrossRef] 
16. Nidumolu, R.; Prahalad, C.K.; Rangaswami, M.R. Why sustainability is now the key driver of innovation. Harv. Bus. Rev. 2009, 87, 56-64. [CrossRef]

17. Ávila, L.; Rossato Facco, L.; Bento, M.; Mendes, A.; Obregon, L.; Trevisan, M. Sustainability and education for sustainability: An analysis of publications from the last decade. Environ. Qual. Manag. 2018, 27, 107-118. [CrossRef]

18. Lozano, R.; Ceulemans, K.; Alonso-Almeida, M.; Huisingh, D.; Lozano, F.J.; Waas, T.; Lambrechts, W.; Lukman, R.; Hugé, J. A review of commitment and implementation of sustainable development in higher education: Results from a worldwide survey. J. Clean. Prod. 2015, 108, 1-18. [CrossRef]

19. Ryan, A.; Tibury, D.; Corcoran, B.P.; Abe, O.; Nomura, K. Sustainability in higher education in the Asia Pacific: Developments, challenges, and prospects. Int. J. Sustain. High. Educ. 2010, 11, 106-119. [CrossRef]

20. Wright, T. Definitions and frameworks for environmental sustainability in higher education. Int. J. Sustain. High. Educ. 2002, 3, 203-220. [CrossRef]

21. Yarime, M.; Tanaka, Y. The issues and methodologies in sustainability assessment tools for higher education institutions: A review of recent trends and future challenges. J. Educ. Sustain. Dev. 2012, 6. [CrossRef]

22. UNESCO. Global Action Programme on Education for Sustainable development; United Nations Educational, Scientific and Cultural Organization: Paris, France, 2015.

23. Ceulemants, K.; Lozano, R.; Alonso-Almeida, M. Sustainability reporting in higher education: Interconnecting the reporting process and organizational change management for sustainability. Sustainability 2015, 7, 8881-8903. [CrossRef]

24. Schmitt, C.T.; Palm, S. Sustainability at German Universities: The University of Hamburg as a Case Study for Sustainability-Oriented Organizational Development. In Handbook of Sustainability Science and Research; Filho, W.L., Ed.; World Sustainability Series; Springer: Hamburg, Germany, 2018.

25. Cortese, A.D. The critical role of higher education in creating a sustainable future. Plan. High. Educ. 2003, $31,15-22$.

26. Winter, J.; Cotton, D. Making the hidden curriculum visible: Sustainability literacy in higher education. Environ. Educ. Res. 2012, 18, 783-796. [CrossRef]

27. Djordjevic, A.; Cotton, D. Communicating the sustainability message in higher education institutions. Int. J. Sustain. High. Educ. 2011, 12, 381-394. [CrossRef]

28. Moore, J. Barriers and pathways to crating sustainability education programs: Policy, rhetoric and reality. Environ. Educ. Res. 2005, 11, 237-555. [CrossRef]

29. Painter-Morland, M. Philosophical assumptions undermining responsible management education. J. Manag. Dev. 2015, 34, 61-75. [CrossRef]

30. Moore, J. Seven recommendations for creating sustainability education at the university level: A guide for change agents. Int. J. Sustain. High. Educ. 2005, 6, 326-339. [CrossRef]

31. O’Byrne, D.; Dripps, W.; Nicholas, K.A. Teaching and learning sustainability: An assessment of the curriculum content and structure of sustainability degree programs in higher education. Integr. Sustain. Sci. 2015, 10, 43-59. [CrossRef]

32. Geli de Ciurana, A.M.; Leal Filho, W. Education for sustainability in university studies: Experiences from a project involving European and Latin American universities. Int. J. Sustain. High. Educ. 2006, 7, 81-93. [CrossRef]

33. Lidgren, A.H.; Rodhe, D. A systemic approach to incorporate sustainability into university courses and curricula. J. Clean. Prod. 2006, 14, 797-809. [CrossRef]

34. Alshuwaikhat, H.M.; Abubakar, I. An integrated approach to achieving campus sustainability: Assessment of the current campus environmental management practices. J. Clean. Prod. 2008, 16, 1777-1785. [CrossRef]

35. Evans, J.; Jones, R.; Karvonen, A.; Millard, L.; Wendler, J. Living las and co-production: U iversity campuses as platforms for sustainability science. Curr. Opin. Environ. Sustain. 2015, 16, 1-6. [CrossRef]

36. Marisiske, R. La universidad de México: Historia y Desarrollo. Rev. Hist. Educ. Latinoam. 2006, 8, 11-34.

37. Ezcurra, E.; Mazari-Hirat, M. Are megacities viable? A cautionary tale form Mexico City. Environment 1996, 38, 6-15. [PubMed]

38. Keivani, R. A review of the main challenges to urban sustainability. Int. J. Urban Sustain. Dev. 2009, 1, 5-16. [CrossRef]

39. UNESCO WEB PAGE. Available online: https:/ / whc.unesco.org/es/list/1250 (accessed on 22 June 2018). 
40. Portal de Estadística Universitaria, UNAM. Available online: http://www.estadistica.unam.mx (accessed on 20 May 2018).

41. Zilahy, G.; Huising, D. The roles of academia in Regional Sustainability Initiatives. J. Clean. Prod. 2009, 17, 1057-1066. [CrossRef]

42. Trencher, G.; Bai, X.; Evans, J.; McCormick, K.; Yarime, M. University partnerships for co-designing and co-producing urban sustainability. Glob. Environ. Chang. 2014, 8, 153-165. [CrossRef]

43. REPSA. Available online: https:/ / www.repsa.unam.mx (accessed on 20 May 2018).

44. PUMAGUA. Available online: http:/ / www.pumagua.unam.mx (accessed on 25 May 2018).

45. Observatorio del Agua. Available online: http://www.observatoriodelagua.unam.mx (accessed on 25 May 2018).

46. ECOPUMA. Available online: https:/ / ecopuma.unam.mx (accessed on 30 May 2018).

47. Basura Cero, UNAM Campus Morelos. Available online: http://www.morelos.unammx/basuracero/inicio (accessed on 27 May 2018).

48. ENES León. Available online: http://enes.unam.mx/?lang=es_MX\&pl=el-campus-sostenible (accessed on 28 May 2018).

49. Ferrer-Balas, D.; Adachi, J.; Banas, S.; Davidson, C.I.; Hoshikoshi, A.; Mishra, A.; Motodoa, Y.; Onga, M.; Ostwald, M. An international comparative analysis of sustainability transformation across seven universities. Int. J. Sustain. High. Educ. 2008, 9, 295-316. [CrossRef]

50. Lukman, R.; Glavič, P. What are the key elements of a sustainable university? Clean Technol. Environ. Policy 2007, 9, 103-114. [CrossRef]

51. Amaral, L.P. Quest for a sustainable university: A review. Int. J. Sustain. High. Educ. 2015, 16, 155-172. [CrossRef]

52. Aleixo, A.M.; Leal, S.; Azeiteiro, U.M. Conceptualization of sustainable higher education institutions, roles, barrier, san challenges for sustainability: An exploratory study in Portugal. J. Clean. Prod. 2018, 172, 1664-1673. [CrossRef]

53. Ven Weenen, H. Towards a vision of a sustainable university. Int. J. Sustain. High. Educ. 2000, 1, $20-34$. [CrossRef]

54. Sharp, L. Green campuses: The road from little victories to systematic transformation. Int. J. Sustain. High. Educ. 2002, 3, 128-145. [CrossRef]

55. Lotz-Sasitka, H. Stories of transformation. Int. J. Sustain. High. Educ. 2004, 5, 8-10. [CrossRef] 